\title{
HACER FORTUNA EN LA EXPANSIÓN MERCANTIL BAJOMEDIEVAL. TRES GRANDES EMPRESAS DE NEGOCIOS DE ZARAGOZA A COMIENZOS DEL SIGLO XV
}

\author{
MAKING A FORTUNE IN THE LATE MEDIEVAL COMMERCIAL EXPANSION. \\ THREE INTERNATIONAL FIRMS IN ZARAGOZA BY THE BEGINNING \\ OF THE $15^{\text {TH }}$ CENTURY
}

Sandra de la Torre Gonzalo

Grupo de investigación CEMA

\begin{abstract}
Resumen: Este trabajo presenta los resultados de mi tesis doctoral, que explora los objetivos y estrategias de las tres mayores empresas mercantiles de Zaragoza entre 1380 y 1430 . La investigación se ha basado en el estudio de casos a partir de fuentes notariales para ofrecer una visión comparativa de los agentes sociales de la expansión comercial del reino de Aragón al final de la Edad Media. Este estudio profundiza en la abundante historiografía existente sobre mercados, economía institucional y elites urbanas, buscando contribuir a los debates actuales sobre formación del Estado moderno y desarrollo económico de la Europa premoderna.
\end{abstract}

Palabras clave: Elites urbanas, Mercaderes, Banca, Historia Económica, Corona de Aragón.

\begin{abstract}
This paper presents an overview of the findings of my doctoral dissertation, that explores the targets sought and the strategies performed by the three major firms settled in Zaragoza during the period 1380-1430. The research has relied heavily on notarial records, and offers a comparative insight into the social agents of the commercial expansion of the kingdom of Aragon. Thus, it builds further on the already extensive scholarship about trade, institutional economics, and urban elites, and seeks to contribute to the current debates on state-formation and economic development of pre-modern Europe.
\end{abstract}

Key words: Urban elites, Merchants, Banking, Economic History, Medieval Crown of Aragon. 
«Entre los altres oficis que posen la cosa pública en bon estament són los mercaders, car terra on mercaderia corre e abunda, tostemps és plena, e fèrtil e en bon estament.»

Francesc Eiximenis, Regiment de la cosa pública, capitol XXXIII

El fragmento del franciscano reivindica por sí solo el papel que jugaron en el pasado los intercambios comerciales. El apoyo doctrinal desde la Iglesia a las nuevas oligarquías urbanas no deja lugar a dudas del cambio de mentalidad y los diferentes valores de la sociedad medieval europea respecto a momentos anteriores. Cada vez son más los estudios históricos que incluyen la Edad Media dentro de los análisis económicos de larga duración (van Zanden, 2001) y el interés actual por las dinámicas de crisis y crecimiento económico han situado en el centro de las miradas este momento de especial relevancia en el desarrollo del sistema económico hispano en época preindustrial (Álvarez/Prados, 2013).

Hace cinco años perfilamos la propuesta de tesis doctoral con un trabajo que se insertaba en un plan ambicioso de largo recorrido. ${ }^{2}$ La respuesta a la pregunta que entonces nos formulamos sobre las implicaciones de la existencia de un puñado de grandes operadores económicos asentados en Zaragoza entre 1380 y 1430 llegó de la historia social, apoyada en un análisis cuantitativo de los datos económicos disponibles, para ofrecer una invitación a asomarse a los negocios al más alto nivel en el Aragón bajomedieval. ${ }^{3}$ Esta perspectiva ha

1 Eiximenis, 1980: 168.

2 Véase Navarro, 2014, que traza un estado de la cuestión de las investigaciones en materia de historia económica en Zaragoza y Valencia. Esta investigación predoctoral se desarrolló en el Departamento de Historia Medieval, CC y TT Historiográficas, y Estudios Árabes e Islámicos de la Universidad de Zaragoza gracias a una beca de Formación de Personal Investigador en el Proyecto «Mercados y desarrollo en Aragón (1250-1500): vínculos mediterráneos, distribución, abastecimiento urbano y costes de transacción en una economía bajomedieval» (ref. HAR-2009-12280), liderado por Carlos Laliena, y al amparo del Grupo CEMA, cuyo investigador principal es J. Ángel Sesma. La tesis «La elite mercantil y financiera de Zaragoza en el primer tercio del siglo xv (1380-1430)», dirigida por Carlos Laliena, fue defendida en la Universidad de Zaragoza el 18 de enero de 2016, obteniendo la mención europea y sobresaliente cum laude, además de la propuesta a premio extraordinario de doctorado. El tribunal examinador estuvo compuesto por las doctoras y doctores David Igual, Angela Orlandi, Hilario Casado, Pere Ortí y M. a del Carmen García. A ellos y a los miembros suplentes, Concepción Villanueva y Sergio Tognetti, quiero hacer extensivos los agradecimientos a los profesores que me han acogido en sus grupos y proyectos de investigación, especialmente por sus valiosos comentarios y sugerencias, como también a Martine Charageat y Michael Limberger, responsables de los informes externos de la tesis, y a Carlos Laliena y María Viu, que leyeron la versión preliminar de este texto.

3 Trabajos previos habían permitido constatar su importancia (Sesma/Laliena, 2009; Laliena/Lafuente, 2012; Sesma, 2013a). Los primeros resultados de la investigación se presentaron a la comunidad científica en encuentros internacionales (The Cambridge Group for the History of Population and 
visibilizado la capacidad de las actividades financieras y comerciales llevadas a cabo por esta elite de poder para explicar la transformación económica, política y social que tuvo lugar en el reino en las últimas centurias de la Edad Media y comprobar, además, el distinto calado regional que manifestó este proceso a nivel europeo.

\section{Las implicaciones de la mercantilización de la sociedad aragonesa}

La orientación del tema y las preguntas planteadas fueron el resultado de lecturas y reflexiones suscitadas por el contacto en centros de investigación europeos con diferentes colegas y modos de trabajar. Primero fue la historia de los mercaderes, después la historia económica anglosajona y, finalmente, la historia urbana de los Países Bajos (Tanzini/Tognetti, 2014; Abulafia, 2005; Murray, 2005; Gelderblom, 2013). No obstante, a pesar de que estas experiencias y lecturas fueron orientando el trabajo, éste presentaba su propia realidad histórica y unas fuentes precisas a las que interrogar para configurar el enfoque final de la tesis doctoral, que no resultó ser una respuesta mimética a lo que se había hecho en otros lugares, ${ }^{4}$ ni tampoco un intento de exaltación de los logros conseguidos en el pasado. El comportamiento de la elite de negocios de Zaragoza es la expresión de factores culturales e institucionales que se encuentran detrás del desarrollo político y económico de la región a finales del siglo XIV y comienzos del XV, de modo que, aunque la ausencia de estudios no justificaba por sí sola la realización de una tesis doctoral, la falta de reconocimiento historiográfico de la importancia del comercio interior frente al marítimo fue un potente estímulo para evaluar el papel de la capital aragonesa como centro económico regional e internacional. ${ }^{5}$

A la hora de marcar las coordenadas de la investigación a desarrollar, partimos de la constatación de la importancia de un reducido grupo de mercaderes de la capital aragonesa que aparecían actuando en los mercados de produc-

Social Structure, Centre for Urban History -Amberes-, International Medieval Congress -Leeds-, École d'été d'histoire économique, European Social Science History Congress) y publicaciones (De la Torre, 2013a, 2014a, 2014b).

4 El ejemplo más próximo sería el trabajo de Marshall, 1999.

5 La mayoría de investigaciones se habían centrado en las grandes ciudades mediterráneas y en el comercio a larga distancia (Coulon, 2004), un hecho que contrastaba con el enfoque regional y el análisis de redes urbanas (Stabel, 1997), que había renovado su vigencia en los últimos años. 
tos (desde el grano a los paños), que movilizaban sumas de dinero muy elevadas a través de la formación de compañías comerciales, y que intervenían a gran escala en la financiación de la actividad estatal y en el mercado de la deuda pública institucional (De la Torre, 2012). Por todo ello, quedaba claro que se trataba de personajes de amplísima influencia social y una dimensión política excepcional en la coyuntura inmediatamente anterior a la aparición del fenómeno de los 'conversos', momento en el que quedó alterada significativamente la composición de las elites urbanas en la Corona de Aragón (Sesma, 1991).

Zaragoza era en ese momento una ciudad de considerable tamaño, capital del reino de Aragón, que contaba con instituciones propias dotadas de capacidad decisoria en materia administrativa, fiscal y de control del gobierno, y que capitaneaba una región interior muy vinculada con los espacios mediterráneos e intensamente comercializada gracias a una especialización de la producción con una amplia aceptación en los ámbitos mercantiles europeos (Laliena, 2012). Igualmente, el núcleo cronológico propuesto se concentra en cincuenta años que aportan argumentos más que suficientes de la importancia de las grandes empresas mercantiles de la Baja Edad Media como objeto de investigación adecuado para abordar determinados problemas sometidos a debate hoy en día (Sesma, 2010).

Precisamente, la primera tarea delicada de la tesis fue definir el objeto de estudio. Íbamos a fijar nuestra atención en el círculo más restringido de los intercambios, esto es, en una elite. Concretamente, en las tres grandes empresas dedicadas al comercio y las finanzas establecidas en Zaragoza entre 1380 y 1430. Éstas comprendían un conjunto muy reducido de personas que se situaban en el escalón más alto de los negocios de la capital aragonesa y que formaron parte, por su importancia económica y social, de la elite de poder del reino (Sesma/Laliena, 2004). Sin embargo, una vez que tomamos contacto con las fuentes, quedó sobre la mesa una pluralidad de ocupaciones, actividades y sociedades que se compaginaba con la diversidad de las caracterizaciones jurídicas, profesionales y personales de nuestros sujetos de estudio. ${ }^{6}$ Se dibujaba así un grupo social cuyos miembros se identificaban por unos intereses (económicos, sociales, políticos) coincidentes y que poseían una identidad distintiva basada en unos comportamientos compartidos que les movilizaban, les aproximaban a las capas más altas de la sociedad y les separaban de los profesionales 
de menor categoría. ${ }^{7}$ Es más, según avanzaba la investigación, la categoría de 'mercader' (con la que se definían nuestros protagonistas masculinos en la documentación zaragozana) no alcanzaba a sintetizar sus actividades profesionales, pues eran comerciantes, banqueros, terratenientes e industriales, todo a un tiempo. ${ }^{8}$ De hecho, la mención expresa en el título de la tesis a una elite mercantil y financiera responde a nuestra convicción de que no es posible estudiar los intercambios comerciales sin comprender el papel del mercado financiero, pues una separación neta entre ambos ambientes es del todo inusual en el siglo Xv (Igual, 2014; Casado, 2015).

\subsection{Una historia económica de una elite social}

Este esfuerzo de definición respondía a uno de los objetivos de la tesis doctoral, que era servir de base comparativa para elaborar cualquier trabajo de síntesis que exige el estado actual de nuestro conocimiento sobre las etapas del comercio regional y el funcionamiento de los primeros mercados financieros en la Corona de Aragón.

\subsubsection{Viejos temas y nuevas líneas de investigación sobre los mercados}

En su desarrollo, la investigación contó con una sólida base en los estudios clásicos, algunos de los cuales ya habían tratado ciertas cuestiones y preguntas que nos hacemos hoy; pero también asumimos los nuevos retos propuestos por la historiografía reciente, enriquecida últimamente con puntos de vista, conceptos y metodologías innovadores. ${ }^{9}$ La línea teórica que más se hace sentir en la tesis doctoral quizá sea la de los análisis regionales y el marco del mercado (Zuijderduijn, 2009; Dijkman, 2011), que han precisado en las últimas décadas el impacto de la comercialización de las sociedades europeas en el desarrollo económico del final de la Edad Media (Kowaleski, 1995; Epstein, 2009), donde la importancia de las elites internacionales y del comercio de gran recorrido se inserta de una manera nueva (Britnell, 2001). En el contexto historiográfico

7 Sobre esta división en el seno de los operadores económicos, véase Guarducci, 1990.

8 Esta realidad que supera la definición clásica de 'mercaderes-banqueros' es ampliamente aceptada: Hunt/Murray, 1999.

9 Un buen ejemplo lo constituye el renovado interés por los aspectos culturales de los intercambios desde un punto de vista institucional: Greif, 2006; Mokyr, 2008; Ogilvie, 2011. Además, la historiografía ha recuperado el interés por los orígenes de la banca moderna y la denominada 'revolución financiera' (Schofield/Mayhew, 2002; Fanfani, 2003). 
más inmediato, la tesis doctoral completa la imagen de la Corona de Aragón que ofrecen los estudios sobre los intercambios en las metrópolis costeras de Barcelona (Carrère, 1978; Coulon, 2004; Soldani, 2010) o Valencia (GuiralHadziiossif, 1989; Igual, 1998; Cruselles, 2011), y llama la atención sobre las regiones interiores del Mediterráneo, en línea con trabajos recientes (Laliena/ Lafuente, 2012).

\subsubsection{Los protocolos notariales y tres estudios de caso}

Dados los interrogantes a los que se pretendía dar una respuesta y las condiciones materiales y temporales para la realización del estudio, fue necesaria la acotación de fuentes para conseguir un análisis en profundidad de un puñado de individuos, cuyas relaciones, eso sí, podrían habernos llevado varias décadas de investigación. La base documental de la tesis doctoral se construyó sobre los protocolos notariales de Zaragoza. Conviene recordar que el volumen de información que éstos ofrecen es muy variable, pues depende de la producción de cada profesional y de la conservación de estos libros (un problema que nos ha afectado especialmente cuando se trataba de los notarios con los que nuestros sujetos trabaron una relación más estrecha). Los tipos documentales más comunes que se manejan son las cartas de procuración, expedidas para la representación ante tribunales, acompañamiento de mercancías y presentación de franquicias, o el cobro de rentas y deudas, seguidas de las comandas y reconocimientos de deudas, y albaranes de todo tipo (censales y rentas de inmuebles, mayoritariamente). Muy por detrás en número y frecuencia, encontramos compra-ventas, ajustes de cuentas (por servicios prestados, finalización de una compañía, etc.) y testamentos. Relativos a procesos judiciales constan sentencias y, más corrientemente, arbitrajes, mientras los inventarios o ejecuciones de bienes aparecen excepcionalmente en nuestro corpus. Las capitulaciones matrimoniales y los contratos de constitución y formación de compañías escasean. Todos ellos en conjunto ofrecen en el detalle un rico panorama, máxime cuando los notarios zaragozanos, que empleaban preferentemente la lengua romance (aragonés y catalán) para escriturar sus actos, dejaron constancia de usos legales y peculiaridades lingüísticas de su clientela. ${ }^{10}$

Con el fin de completar esta imagen y de evitar, al mismo tiempo, una visión sesgada, se optó por obtener un muestreo de documentación de otro tipo y procedencia suficientemente representativo, a pesar de ofrecer como resulta- 
do un corpus documental de naturaleza muy dispar. La carencia de documentación concejil contable en Zaragoza para las fechas que nos ocupaban fue suplida con los instrumentos registrados en sus protocolos por los notarios que en algún momento estuvieron al servicio de estas instituciones (Lafuente, 2016), mientras los privilegios, ordenanzas municipales y primeros pregones del gobierno urbano se trabajaron a partir de ediciones (Falcón, 2010 y 2011; Villanueva/Lafuente, 2015).

\section{Cuadro 1. Principales fondos archivísticos empleados}

\begin{tabular}{|c|c|c|}
\hline TIPO & ARCHIVO & DOCUMENTO \\
\hline $\begin{array}{l}\text { - Documentación } \\
\text { Privada }\end{array}$ & $\begin{array}{l}\text { - Archivo Histórico de Protocolos Notariales de } \\
\text { - Aaragoza (AHPNZ) } \\
\text { - Archivo Histórico Provincial de Zaragoza (AHPZ) } \\
\text { - Archivo Municipal de Zaragoza (AMZ) } \\
\text { - Arxiu Històric de la Ciutat de Barcelona (AHCB) } \\
\text { - Archivo Capitular de Barcelona } \\
\text { - Arxiu Comarcal del Bages: protocolos notariales de } \\
\text { Manresa } \\
\text { - Archivo Histórico Nacional (AHN) } \\
\text { - Archivo de la Corona de Aragón (ACA) } \\
\text { - Archivos de la Diputación de Zaragoza (AHDZ) } \\
\text { - Archivo Diocesano de Zaragoza (ADZ), "Extrava- } \\
\text { gantes" } \\
\text { - Archivo Histórico Provincial de Teruel (AHPTE) } \\
\text { - Arxiu Nacional de Catalunya (ANC) } \\
\text { - Biblioteca Nacional de Catalunya (BNC) } \\
\text { - Arxiu del Castell de Vilassar de Dalt } \\
\text { - Biblioteca Nacional } \\
\text { - Areal Academia de la Historia } \\
\text { - Archivio di Stato di Prato, Fondo Datini }\end{array}$ & $\begin{array}{l}\text { - Real Patrimonio } \\
\text { - Maestre Racional } \\
\text { - Registros de Canci- } \\
\text { llería } \\
\text { - Cartas reales } \\
\text { - Comunidad de Al- } \\
\text { deas de Daroca } \\
\text { - Comunidad de } \\
\text { Aldeas de Teruel } \\
\text { - Diputación del Reino } \\
\text { de Aragón } \\
\text { - Corte del Arzobispo } \\
\text { de Zaragoza }\end{array}$ \\
\hline
\end{tabular}

Los fondos catalanes ayudaron a poner en contexto las actividades de las grandes empresas zaragozanas. Por su parte, los archivos familiares de la nobleza aragonesa proporcionaron testamentos, traspasos de propiedades (señoríos muy especialmente) e información genealógica y patrimonial complementaria interesante. El hecho de que la Comunidad de aldeas de Teruel haya mantenido su archivo muy completo y que la de Daroca conserve prácticamente completas las series de albaranes expedidos por los propietarios de su deuda pública durante el último cuarto del siglo XIV y todo el siglo Xv, nos permitió 
contar con noticias muy relevantes sobre la gestión hacendística y financiación de estas instituciones. ${ }^{11}$ Entre este tipo de documentación contable, las piezas más excepcionales para nuestro estudio fueron los volúmenes entregados por el tesorero de la hacienda del reino o del arrendador de los ingresos del mismo a la Diputación de Aragón, dado que ofrecen una rica información sobre el funcionamiento económico de la institución, además de listados completos de acreedores del reino. ${ }^{12}$ Aunque, sin lugar a dudas, el Archivo de la Corona de Aragón resultó fundamental a la hora de aportar nuevas perspectivas a los negocios de las grandes empresas zaragozanas gracias a los volúmenes del fondo del 'Maestre Racional'. Los libros de la tesorería del rey, reina e infantes se vaciaron sistemáticamente y acudimos de manera puntual a pergaminos, cartas reales y registros de la Real Cancillería en busca de referencias o fechas conocidas.

Por último, la edición de las reuniones de Cortes y Parlamentos puso a nuestra disposición referencias directas a cuestiones legislativas (actos de corte, fueros), judiciales (greuges o agravios contra el rey y sus oficiales) y económicas (imposición de exacciones, ajustes de cuentas) que preocupaban a los representantes aragoneses y, muy especialmente, nos orientó sobre el funcionamiento de la hacienda del reino. Además, estas actas incluían noticias útiles que completaron y perfilaron las biografías de nuestros protagonistas masculinos con su asistencia a las sesiones, su presencia en comisiones y embajadas, el desempeño de cargos de representación o de otro tipo, o su participación en campañas militares.

En lo que respecta al tratamiento de los datos obtenidos de fuentes tan dispares e incompletas, teníamos claro que la metodología debía responder a nuestro objetivo de abordar un tema de historia económica. La novedad de

11 La dispersión de los intereses de las grandes empresas mercantiles zaragozanas generó una abundante información que se ha conservado en parte en los archivos locales, cuya documentación hemos podido consultar en buena medida gracias a plataformas como Documentos y Archivos de Aragón (disponible en: www.sipca.es/dara, consultada el 18/05/2016) y Arxius en línia (disponible en: http://arxiusenlinia. cultura.gencat.cat/ArxiusEnLinia, consultada el 18/05/2016).

12 Dentro del periodo estudiado, se conservan los siguientes libros de cuentas del General del reino, del tesorero y libros de la administración: Archivo de la Diputación Provincial de Zaragoza, 8 (14101418), 12 (1417-1418), 13 (1420-1421), 14 (1428-1429), 758/8 (1430), 16 (1432-1433), 758/3 (14351436) y $758 / 6$ (1435). Otras fuentes económicas aragonesas de primer orden como son las cuentas supervivientes de la percepción de las generalidades en diferentes puestos aduaneros del reino, se refieren a los años centrales del siglo xv y escapan de nuestro marco cronológico, aunque hemos recurrido a las ediciones disponibles (la mayoría a cargo de J. Á. Sesma) para establecer un marco comparativo: Lafuente, 2015. 
nuestro enfoque en la historiografía de la Corona de Aragón medieval residía en interrogamos por los componentes sociales y políticos de las actividades económicas, y no al contrario. Tomamos de la prosopografía ${ }^{13}$ las herramientas para abordar los estudios de caso que nos permitieron comprobar las diferentes opciones adoptadas en el plano económico, político y social por nuestros sujetos de estudio, que determinaron la formación y evolución de su patrimonio, las estrategias de inversión de capital y de gestión de su riqueza, los procesos de afirmación social o su recorrido político. Los seiscientos años que nos separaban de estas personas nos permitieron tomar suficiente distancia para que el análisis de sus actividades no fuera «un ejercicio erudito o de exaltación biográfica (o hagiográfica)», ${ }^{14}$ sino que nos encaminara hacia problemas sociales profundamente vinculados al desarrollo económico. La reconstrucción de las trayectorias de las tres empresas (Donsancho, Coscó y Casaldáguila) más destacadas de la ciudad durante los cincuenta años que abarcaba este estudio sirvió para ilustrar los aspectos tratados. Optamos por una solución a medio camino entre la biografía y la prosopografía, de manera que los ejemplos excepcionales se situaran frente a los comportamientos habituales, tratando de no caer tampoco en la generalización gratuita. Asimismo, la noción de red como estructuración de los universos sociales resultó un modelo explicativo altamente aprovechable (Coulon, 2010). La introducción de este concepto (y como tal metáfora debe ser tomada en esta investigación, ya que no se pretendió llevar a cabo un 'análisis de redes sociales') facilitó reparar conjuntamente en sujetos, instituciones y lugares dentro de un sistema reticular en torno a centros que articulaban mallas más complejas, y comprender así mejor la realidad del Aragón bajomedieval.

\section{Componentes económicos y sociales del éxito mercantil en la Corona de Aragón bajomedieval}

A la hora de reflejar los resultados de la investigación por escrito, la estructura interna de la tesis buscó reflejar lo argumentado en las líneas precedentes. Tras una introducción que contiene la presentación del trabajo (en inglés), una síntesis de las principales líneas de investigación y del estado de la cuestión, y

13 Contábamos con ejemplos recientes de aplicación del método prosopográfico en investigaciones próximas sobre mercaderes y elites urbanas: Cruselles, 2001; Iranzo, 2005; Mainé, 2006; Lozano, 2008.

14 Priotti, 2002: 15. 
un marco histórico que contextualiza el estudio, en la primera parte se definen los mecanismos que sustentaban la trama industrial, comercial y bancaria de las grandes empresas a través de su estructura patrimonial y su organización interna. La segunda parte está dedicada al examen detallado de las actividades e inversiones, entre las que predominaron las financieras. En la tercera parte se establece la incidencia que esta elite tuvo en los procesos sociales y políticos que experimentó la capital aragonesa y el conjunto del reino. Cierran la parte expositiva unas conclusiones generales (en inglés) que amplían las conclusiones parciales que acompañan a cada capítulo. Finalmente, los anexos recogen los materiales que sirven de apoyatura a la explicación y una selección bibliográfica recupera los títulos más empleados. En conjunto, los resultados de la investigación han sido desiguales. Por un lado, las fuentes presentaban limitaciones y, por el otro, algunos de los temas planteados habrían requerido de otros trabajos monográficos que sirvieran de apoyo a nuestro análisis. La mayor laguna de este estudio tiene que ver con las actividades concretas y el rastreo de los orígenes sociales; no ha sido posible descender hasta el nivel de detalle de calidades de los productos, proveedores, clientes, organización interna, comunicación e información mercantiles. ${ }^{15}$

\subsection{Grandes patrimonios: de los centros regionales productores de textil a la financiación de las instituciones}

Si bien los aspectos culturales y simbólicos son interesantísimos, no debemos perder de vista que la afirmación social y política, personal y familiar venía dada en las sociedades urbanas medievales por el éxito económico y la acumulación de riqueza (Sabaté, 2008), lo que nos conduce a explorar la estructura, funcionamiento y estrategias patrimoniales de las tres grandes empresas de Zaragoza. ${ }^{16}$ Las características de la fortuna personal de Juan Donsancho, Beltrán de Coscó y Ramón de Casaldáguila se perfilaron en referencia a la composición de sus ingresos e inversiones en mercados públicos y privados, lo que permitió proponer el camino específico que seguía la constitución

15 Actualmente, María Viu se ocupa en su investigación doctoral (desarrollada en el Departamento de Historia Medieval de la Universidad de Zaragoza bajo la dirección de Carlos Laliena) de desvelar estos aspectos a partir de un análisis en profundidad de los libros contables de las compañías del aragonés Joan de Torralba, ciudadano de Barcelona, que operaba preferentemente en Aragón e Italia en los años centrales del siglo xv.

16 El enfoque no es una novedad, pero no ha sido muy explorado en la historiografía medieval: Goldthwaite, 1968 . 
Hacer fortuna en la expansión mercantil bajomedieval. Tres grandes empresas de negocios...

Cuadro 2. Patrimonio de Beltrán de Coscó en 1410 a partir de su testamento y codicilos

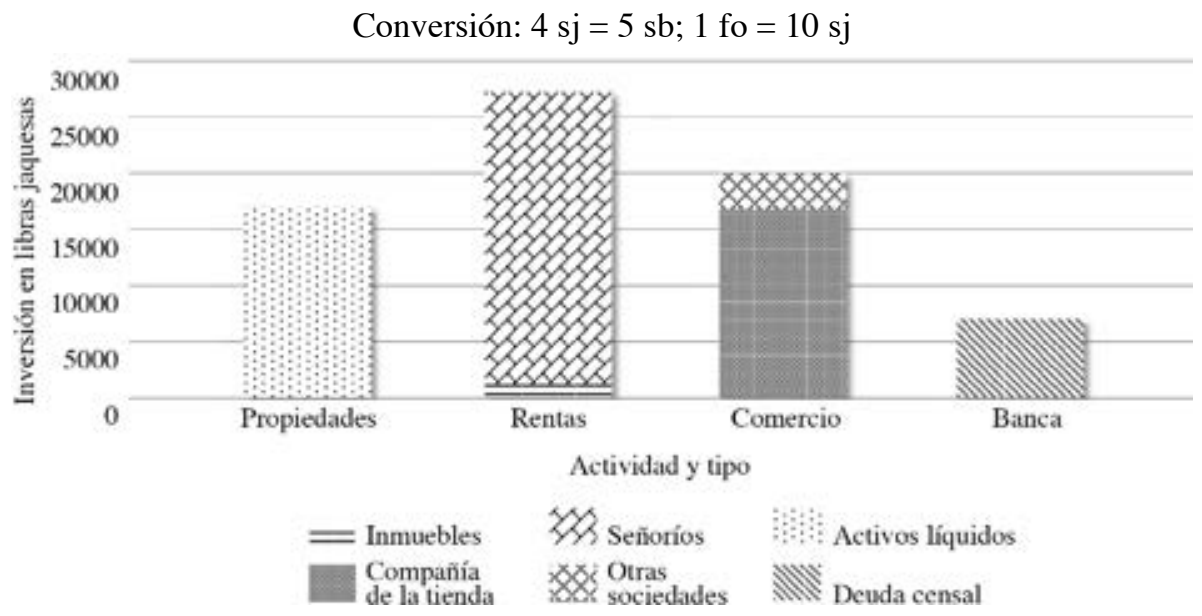

de los grandes capitales mercantiles de Aragón en este periodo: desde su origen en los centros económicos regionales hasta la captación de oportunidades excepcionales como la creación de los dos grandes negocios de finales del siglo XIV (la deuda pública censal y el impuesto de las generalidades, con la consiguiente implantación del sistema de arrendamientos) ${ }^{17}$ y la relación con el gran capital judío.

Sorprende la capacidad de movilización de capitales de estas empresas. ${ }^{18}$ Beltrán de Coscó tenía reservadas en 1410, poco antes de fallecer, unas 10.500 libras jaquesas (21.000 florines de oro) en metálico para hacer efectiva al noble Pedro Jiménez de Urrea parte de la compra de un señorío. Según sus últimas voluntades, llegó a acumular un patrimonio personal aproximado de 100.000 libras jaquesas, de las cuales, algo menos del $20 \%$ se correspondían con sociedades comerciales (la sociedad de la tienda y una participación en dos compañías al quart diner, esto es, una cuarta parte para el comanditario y tres para el comitente), dos terceras partes con inmuebles en alquiler y títulos de deuda

17 Acerca de este gran aparato recaudador, véase Sesma, 2013b.

18 La versión completa de la tesis doctoral es de acceso libre a través del repositorio institucional de la Universidad de Zaragoza en la dirección https://zaguan.unizar.es/record/48292. Por ello, el texto se ha aligerado de referencias bibliográficas y se ha prescindido de las citas documentales, ya que allí se explican mejor los razonamientos que aquí están abreviados y se da merecido crédito a las investigaciones de colegas. 
(ingresaba 2.500 libras procedentes del crédito censal cada año y 123 libras de inmuebles urbanos y fincas rústicas), y el resto con 17.000 libras de liquidez y 26.000 libras invertidas en señoríos. Tras su muerte, su familia y la de Ramón de Casaldáguila acaparaban en 1417 el 10\% de los intereses satisfechos por el General de Aragón en forma de pensiones anuales por los títulos de deuda que poseían (un 5\% del total emitido por el reino).

Ninguna de las grandes empresas analizadas nació de las 'buenas familias' zaragozanas. Juan Donsancho, aunque de origen altoaragonés, creó su carrera de éxito alrededor de la corte real en Barcelona, y su esposa, Altadona de Mora, pertenecía a una familia de ciudadanos de Tortosa bien relacionada con la jerarquía eclesiástica. Los altoaragoneses Guillem y Pedro de Sora fueron sus hombres de confianza junto al escudero Sancho Lasierra, que tenía su propio obrador de pañería y una participación importante en el que el barcelonés Gabriel Ocello regentaba en Zaragoza a comienzos de siglo. En la misma década de 1370, hallamos en la capital aragonesa a Beltrán de Coscó como cabeza de su propia compañía. De Tárrega llegó con su esposa, Angelina Sesvalls, y también se hizo acompañar de mercaderes de esta localidad, como Guerau Sasala. Rápidamente alcanzó la ciudadanía e integró en su círculo próximo a personajes locales de gran peso en el panorama político de la Corona, tales como el consejero real Miguel de Capiella. Por su parte, la familia de Ramón de Casaldáguila ya era importante en Barcelona (su padre y su suegro formaron parte del Consell de Cent), donde habían llegado con una fortuna amasada en Manresa. De la mano de los mercaderes Francesc Merles y Jaume Despuig, Casaldáguila llevó consigo a la capital aragonesa al filo del cambio de siglo los vínculos creados allí, entre los que cabe destacar al barcelonés Bernat Quintana, que trabajaba estrechamente con la compañía de Francesco Datini en Aragón y al que le unían vínculos de sangre.

Este fenómeno se encuadra dentro de una expansión del capital catalán hacia Aragón evidente ya en el segundo tercio del siglo XIV (Diago, 2013). A finales de la centuria, Zaragoza bullía de actividad económica, alimentándose del éxito de las nuevas sociedades mercantiles tras la irrupción de la Peste y el final de la contienda castellano-aragonesa. El sector textil, la 'locomotora económica' de finales de la Edad Media, experimentaba en las últimas décadas del Trescientos un momento especialmente feliz de protección y estímulo de su industria desde las instituciones de la Corona de Aragón, hasta el punto de ser considerada como utilidad de la cosa pública, de manera que cada centro urbano y estado se afanaba en la defensa de los intereses de este negocio. Los 
cambios políticos (el fin de los privilegios de los bearneses con la invasión de los condes de Foix, en 1398 y el cierre de la frontera en 1403 y la prohibición en 1406 de la importación a Castilla de paños procedentes de la Corona de Aragón) condicionaron las estrategias de las empresas comerciales que operaban atravesando las fronteras pirenaicas y del interior peninsular, pero no impidieron que se produjeran numerosos contactos en forma de sociedades o inversiones en compañías que conectaban el capital mercantil zaragozano con la red de intercambios del sur de Francia o con los flujos del comercio internacional dirigido desde Barcelona, que concebía el mercado castellano como una extensión del aragonés.

\subsection{La tienda y la compañía}

La organización de los negocios sirve de base explicativa para muchas de las cuestiones que se abordan en la tesis. La elite mercantil y financiera de Zaragoza estaba formada por empresas que adoptaron las principales innovaciones en gestión y organización del trabajo desarrolladas en los centros rectores del Occidente medieval. ${ }^{19}$ Socios, factores y agentes se unían a la forma asociativa básica y extendida, la firma familiar, para crear una estructura corporativa más compleja. La compañía fue la fórmula preferida para la ampliación de capital y la expansión empresarial, dada su capacidad de adaptación (tamaño, organización y extensión) a las demandas de las actividades y objetivos de sus miembros. De ahí que nos encontremos con una envergadura limitada de las empresas Donsancho, Coscó y Casaldáguila, lo que no les impidió actuar en términos de igualdad con otras compañías en la Corona de Aragón e incluso desenvolverse con efectividad en la arena del comercio internacional, dados el capital disponible para invertir, su estructura y su capacidad para intervenir directa o indirectamente en los principales mercados del momento.

El negocio textil es la base de las mayores fortunas mercantiles de Zaragoza de finales del siglo xiv; es más, la tienda o botiga es la sede jurídica y física de la empresa. Desde el obrador de pañería que tenía en San Jaime (parroquia que albergaba en la década de 1370 a otros dos pañeros de éxito: Juan Donsancho y el bearnés Arnalt Lasala) hasta el gran patrimonio que transmitió a sus sucesores en 1411, Beltrán de Coscó se sirvió de la fórmula de la compañía para ampliar el capital de la sociedad familiar con la contribución de compañeros (sus

19 Sobre la extensión de estos conocimientos, véase Orlandi, 2014. 
alianzas con Arnalt de Araus, Bernat Ninot y Nicolau de Biota construyeron ramificaciones que abarcaban desde Olorón hasta Barcelona) y luego abrirla a la inversión del patriciado de la capital aragonesa, que encontraba en las taules de mercaderes un lugar seguro para guardar y hacer crecer sus ingresos.

La parte correspondiente a Beltrán de Coscó en la compañía de la tienda estaba en 1404 valorada en 21.000 libras barcelonesas, lo que la sitúa a la cabeza de las sociedades barcelonesas y un capital comparable al de una compañía mediana de la Toscana como era la de Francesco Datini (Nigro, 2010). A la manera del pratense, la familia se valió de la pericia de socios y directores en las sucursales de Zaragoza y Barcelona, que trabajaban de manera autónoma y eran copartícipes de sus pérdidas y beneficios. En sus últimos años, Angelina Sesvalls y Beltrán de Coscó dejaron el contacto directo con clientes y proveedores en manos de Jaime Coscó (al que no les unían vínculos de sangre), una figura similar a Pedro de Sora, que contaba incluso con un espacio de trabajo dentro de la casa familiar de Altadona de Mora y Juan Donsancho. Contamos no menos de siete mercaderes en los actos notariales realizados por la empresa Coscó en 1401, a los que se sumaba una amplia red de representantes provistos de cartas de procuración que hacía posible una planificación de los negocios a gran escala y permitía a las cabezas de las empresas de la capital aragonesa ausentarse de la tienda y vigilar los progresos, concentrándose en las labores de dirección.

Ramón de Casaldáguila creó un sistema de compañías donde un socio principal o un número reducido de compañeros mantenía contratos de sociedad legalmente independientes con regentes en diferentes lugares y/o negocios. A su sombra, muchos mercaderes prosperaron y acabaron encabezando sus propios proyectos, como Joan Tegell, factor de la tienda de Zaragoza, que mantuvo de manera paralela con Juan de Tolosa una sociedad para gestionar una botiga de draperia; Juan Fexas, que formó en 1425 junto a Juan de Manariello la sucursal aragonesa de la compañía Torralba (donde recabaron muchos de los empleados de Casaldáguila); o Juan de Mur, hijo del escudero Alfonso de Mur, recaudador de las generalidades nombrado por el manresano, y que heredó el control de las empresas de Casaldáguila.

\subsection{Negocios oportunos}

El comercio es uno de los aspectos en los que la investigación doctoral menos profundizó, ya que las actas públicas sólo muestran un resumen de los asuntos abarcados por estos grandes agentes económicos, cuyo día a día estaba contenido en sus libros contables, que lamentablemente no se han conservado. 
Aún así, resulta evidente que las empresas de Donsancho, Coscó y Casaldáguila dominaron los sectores económicos que la capital del reino era capaz de controlar, gracias a una tupida red y conexiones con agentes y factores en ciudades, ferias y puertos unidos por lazos familiares con ramificaciones en sus lugares de origen (Caspe, Manresa, Tárrega, Gerona, Olorón), y que no se confinaron a la ruta del Ebro o a los intercambios con el sur de Francia, sino que extendieron sus contactos para intervenir en el comercio atlántico, el transpirenaico y el mediterráneo. Coscó y Casaldáguila trabajaron con la compañía de Francesco Datini para sus intercambios en las ferias hispanas y en plazas internacionales como Brujas o Génova, donde adquirían paños flamencos para las coronaciones reales o pieles para vestir a la corte. En estos asuntos, la sede zaragozana de los Coscó centralizaba los pedidos que la tienda de Barcelona atendía directamente de la familia real, como los tejidos para decorar el palacio de Bellesguart, retiro de Martín I.

Además de estos productos suntuarios, los objetos de intercambio respondían a los múltiples intereses económicos que las tres empresas eran capaces de asumir: lana y cereales castellanos, hierro navarro y vasco, tejidos del norte de Europa y del sur de Francia, o importaciones del Levante. El río Ebro fue la principal vía de comercio, pero no la única. Nos consta que Donsancho embarcó en una ocasión pastel y azafrán con destino al puerto de Bristol, y que participaba en compañías barcelonesas que intervenían en el comercio de larga distancia entre el Mediterráneo y el Atlántico en la década de 1380. El comercio de tipo especulativo, como los grandes cargamentos de trigo destinados al abastecimiento urbano en momentos de escasez (es el caso de los 3.000 cahíces de trigo enviados por Donsancho a Valencia en 1381 que se beneficiaron de los incentivos municipales a la importación de grano) se combinaba con el cotidiano suministro de materias primas para la industria manufacturera $(\mathrm{Ca}-$ saldáguila enviaba a comienzos del siglo xv por el Ebro cargamentos de más de 2.000 arrobas de lana procedente de Aragón y Castilla a Tortosa). Entre los secretos de su éxito no hay que minusvalorar el peso que el control de las generalidades pudo tener en los aspectos comerciales de las actividades profesionales de Donsancho, Coscó y Casaldáguila, pues estuvieron al frente de una estructura fiscalizadora que permitía tener controlados los precios a pie de calle, contar con enlaces locales y estar al día de las novedades diplomáticas.

Cuando conocemos todas sus actividades e intereses (como en el caso de Beltrán de Coscó gracias a sus últimas voluntades), encontramos capitales distribuidos entre el comercio de lana, cereales y tejidos de su empresa familiar, 
compañías mercantiles con otros colegas, sociedades por partes de arrendamientos de impuestos, rentas señoriales, actividades bancarias, préstamos, inversión en censales y censos sobre propiedades inmuebles. Entre ellas, las actividades financieras sobrepasaron las expectativas iniciales de la investigación debido a su relevancia, complejidad e implicaciones. Frente a la imagen que la historiografía se había creado de un reino de Aragón retrasado especialmente en el desarrollo de la banca (Riu, 1990: 193), es un hecho que la elite financiera y mercantil de Zaragoza actuaba cotidianamente con descubiertos y dinero fiduciario. En 1417, la gente de Ramón de Casaldáguila escrituró títulos de deuda por valor de más de 7.000 libras jaquesas. Avales, pagos aplazados, compras por adelantado y otras formas de crédito constituían más de un $88 \%$ de sus actividades anuales ante el notario Antón de Aldovera. Es más, las principales operaciones que definen la banca moderna (depósitos, cambios y giros) estaban normalizadas entre los agentes económicos locales, que se adaptaron con las nuevas fórmulas a las necesidades de las sociedades, negocios y clientela del mercado aragonés (Conde, 1988).

La estancias de la corte en Zaragoza dejaron huella en los protocolos de los notarios locales de este tipo de servicios, que estaban a la cabeza del sistema financiero de finales de la Edad Media. Así constatamos el contacto de Coscó y Donsancho con los grandes banqueros de la Corona (Descaus y d'Olivella, Gualbes y d'Usay) para trabajar como mediadores en el tráfico de capitales y numerario. Las cuentas abiertas en las taules de los mercaderes y/o banqueros ofrecían a su clientela facilidades de pago y el movimiento de dinero con instrumentos como la dita (orden de pago al dictado). Juan Donsancho ofreció frecuentemente estos servicios a la corona, apareciendo como ditor e plan pagador de la corte, y son frecuentes en los instrumentos notariales zaragozanos las referencias a estos documentos hológrafos y sellados, que tenían carácter probatorio por sí mismos.

El negocio del dinero no deja de ser una de las facetas del comercio, consistente en comprar y vender capitales en diferentes puntos y obtener el correspondiente beneficio (Sánchez, 2006), pero los préstamos a gran escala asumidos por las empresas Donsancho, Coscó y Casaldáguila abarcaron todos los niveles del crédito (consumo suntuario e inversión son los más significativos) y alcanzaron a amplias capas de la sociedad aragonesa. La solvencia de estos personajes era conocida y por ello actuaban además como avalistas de grandes nombres, tales como el arzobispo zaragozano Lope Fernández de Luna, quien reconoció en su testamento en 1382 que estaba en deuda con Beltrán de Coscó 
por un montante cercano a las 16.000 libras jaquesas, que respondían a empréstitos (mediante el sistema del 'mutuo') y pagos a cuenta a terceros. El targarí trabó una estrecha amistad con Martín de Alpartir, canónigo del Santo Sepulcro y tesorero del prelado, que destacó por su actividad política y de mecenazgo artístico. Coscó era además hermanastro de Arnau Folquet, comendador de la orden de San Juan de Jerusalén, lo que le facilitó tratar de negocios directamente con el castellán de Amposta.

La nobleza aragonesa fue parte principal de la clientela más relevante de Donsancho, Coscó y Casaldáguila, sin duda. Como consecuencia de la pérdida de capacidad para afrontar unos costes en aumento, este sector privilegiado encontró en sus empresas liquidez y métodos crediticios alternativos al préstamo hebreo tradicional, como préstamos (con o sin prenda) e hipotecas, arrendamientos de rentas, emisión de renta constituida (censales y violarios garantizados por los vasallos), y alienación de patrimonio. De una manera semejante se comportó la monarquía. Este negocio contaba con unos componentes extraeconómicos evidentes: detrás de grandes cantidades de dinero que se resolvían con créditos a corto plazo y altos intereses se intuye la existencia de relaciones privilegiadas de estos mercaderes de Zaragoza con la familia real y con el propio monarca, que enajenaba temporalmente piezas de extraordinario valor simbólico o emocional. Esta actividad pone de relieve su potencial para acceder a un mercado del crédito reducido y especial, y competir con otras ciudades de la Corona como Barcelona o Valencia.

Las tres empresas analizadas prestaron sus servicios a la casa real aragonesa, pero es Juan Donsancho quien protagonizó una actividad inédita. De hecho, ofrece un ejemplo excepcional para observar la mecánica de endeudamiento de la corona en el último cuarto del siglo XIv. Sus compañeros eran funcionarios de la Corte, como el aragonés Berenguer de Cortillas y destacados miembros de las familias judías Alazar ${ }^{20}$ y de la Caballería. Todavía en vida de Pedro IV, Donsancho y Cortillas protagonizaron cesiones de censales sobre las aljamas y otros ingresos de la casa del rey (a un elevado 10\% de interés), negociaciones y renegociaciones de crédito a corto plazo (mogubells, remogubells) y ventas con cartas de gracia de rentas de patrimonio real. En 1386, Donsancho estimaba que Violante de Bar y el infante Juan le debían unas 15.500 libras jaquesas (31.000 florines de oro) y, ya como rey, Juan I ingresó

20 Una semblanza de Alazar Golluf, de la tesorería de la reina Violante, puede encontrarse en Blasco, 2009. 
en la cámara de la reina en un solo día cerca de 8.000 libras a través de una operación de emisión de títulos de deuda constituida (ésta tenía, por lo general, una vida corta en estos casos) adquiridos por Beltrán de Coscó, Juan Donsancho y Berenguer de Cortillas. Dada la importancia de los préstamos, Donsancho recibía directamente los ingresos de la monarquía (dispenserías de los infantes, rey o reina), ya fuera porque el dinero entregado por las instituciones era desviado a su cuenta para reducir la deuda contraída, ya porque era él mismo quien recaudaba las rentas o impuestos de manera directa (fue el caso de la Marca o las primicias entregadas por el papa al rey de Aragón).

La fortuna e influencia del mercader aragonés se diluyó con el cambio de siglo. A su nombre se habían hecho inversiones de gran importancia y la excesiva cercanía a la familia real le perjudicó seriamente, ya que su nombre apareció en 1396 en la lista de consejeros reales y otros miembros de la camarilla de Juan I salpicados por el escándalo. Las acusaciones eran muy serias y tenían que ver con una vía de financiación basada en la enajenación del patrimonio real, ${ }^{21}$ iniciada ya por Pedro IV, pero cuya legitimación (basada en las necesidades de defensa de la Corona) había perdido fuerza. El aragonés se vio involucrado en la denuncia de un entramado societario pensado para desviar dinero para el enriquecimiento privado por parte de consejeros, funcionarios reales, y mercaderes extranjeros como Luchino Scarampi. Y, aunque Juan Donsancho no salió mal parado, sus exigencias de cobrar lo adeudado por las arcas reales se toparon con las trabas contables y legales del Maestre Racional. Ante las Cortes reunidas en 1398 reclamó a Martín I en Zaragoza 31.500 libras jaquesas (63.000 florines) que todavía se le adeudaban por asuntos como el matrimonio de la infanta Juana, condesa de Foix.

La caída de la empresa Donsancho coincidió con el ascenso de Beltrán de Coscó y Ramón de Casaldáguila. Mientras el primero se implicaba crecientemente en los negocios de la Corte, Coscó crecía en importancia bajo la protección del arzobispo cesaraugustano y se mantenía ocupado en los asuntos eclesiásticos sin mezclarse con la gestión del patrimonio real y la explotación de sus derechos e impuestos. Al mismo tiempo, atraía hacia sí la simpatía de los bearneses, que le abrieron las puertas hacia el comercio transpirenaico, hasta que un golpe de fortuna hizo que el infante Martín sucediera en el trono a su hermano y sus apoyos se consolidaron así en el poder. Antes de que sus intereses en Aragón llevaran a Ramón de Casaldáguila a instalarse definitivamente 
en Zaragoza hacia 1402, éste operaba desde Barcelona (donde él y su hermano Pere habían alcanzado la ciudadanía) a través de delegados como los barceloneses Pere Godens y Guillem Ferrer, factores de su tienda en la capital del reino, que se hicieron cargo de girar efectivo a la sede papal en Aviñón o del adelanto de dinero hecho a los infanzones aragoneses para que éstos cumplieran con su aportación a la defensa del reino. El salto hacia la posición de preeminencia financiera en la que se colocó Casaldáguila hasta su muerte fue la asunción del quitament de la Comunidad de aldeas de Calatayud. Se trataba de un rescate financiero, en el sentido actual del término, que ya se había intentado realizar sin éxito anteriormente, pero que en 1401 se concretó en un contrato firmado por la Comunidad con Casaldáguila con el objetivo de eliminar una deuda de casi 42.500 libras jaquesas en un plazo de diecisiete años, para lo que la compañía formada para la gestión de este negocio ingresaría de las aldeas más de 5.000 libras anuales. Sólo tres años más tarde, en las Cortes de Maella de 1404, Casaldáguila tuvo la oportunidad de demostrar que estaba capacitado para un proyecto aún mayor: la gestión económica del General de Aragón. Fue su entrada definitiva en la hacienda aragonesa, a cuya cabeza se mantendrá hasta su muerte en 1428 y cuya gestión heredará su último socio, Juan de Mur, un noble dedicado a la mercaduría.

La recaudación de las generalidades era el mayor de los negocios (se llegaron a pagar más de 35.000 libras anuales por su arrendamiento hacia 1415) del reino. Se trataba de un impuesto aduanero que gravaba el tráfico comercial y que toda persona debía abonar sin excepción, de cuya percepción se ocupaban los administradores de la hacienda aragonesa, que además adelantaban los pagos de los salarios de los oficiales o el abono de los intereses de la deuda pública. Destacados mercaderes ocuparon cargos de responsabilidad, como la supervisión de los puestos de aduanas de mayor tráfico comercial, asumida por nombres como Juan Fexas o Miguel Homedes. Esta actividad estaba fiscalizada por los diputados del reino y Casaldáguila respondía ante sus socios e inversores en la compañía gestora del arrendamiento del General. Tras casi dos décadas en solitario, apareció el mercader Jordi de Camprodón, ciudadano de Perpiñán, que en 1420 ejercía como administrador en nombre del manresano, quien figuraba como arrendador principal. A partir de este momento (ciclos de 1423, 1426 y 1428), contamos con más información acerca del complejo entramado que respaldaba el compromiso adquirido por el arrendador, que encabezaba un sistema societario por participaciones semejante al que regía las compañías navieras. 
Sin lugar a dudas, la financiación de las instituciones (a través de la adquisición de deuda pública, el arrendamiento de sus ingresos y la facilitación de transacciones financieras) fue clave en el éxito de Donsancho, Coscó y Casaldáguila. Su envergadura da muestra del amplio calado que consiguieron desde el nivel local al nacional y, muy especialmente, del estímulo que las necesidades de unas instituciones en transformación supuso para la introducción de innovaciones, como fórmulas societarias sofisticadas (un buen ejemplo son las compañías de participaciones que acabamos de mencionar) y el control de los instrumentos económicos más modernos para respaldar actuaciones que implicaron a las grandes empresas de Zaragoza con sociedades judías e italianas que operaban al más alto nivel en la Corona de Aragón con el fin de componer la infraestructura necesaria que hiciera posible, desde la financiación de una campaña militar a Cerdeña en 1409, hasta hacer llegar unas columnas desde Gerona y Barcelona para la construcción de la sede de la Diputación del reino en su capital a mediados de siglo.

\subsection{El poder y la autoridad de los grandes mercaderes: capital económico, capital social y capital simbólico}

El poderío económico de las empresas Donsancho, Coscó y Casaldáguila colaboraba en la construcción de la posición predominante de quienes las integraban, cuya progresión patrimonial, social y política se veía favorecida por la existencia de una relación privilegiada con la monarquía (ventaja considerable sobre la competencia), de una proximidad a la elite política, que facilitaba la confluencia de intereses públicos y privados, y de la realización de inversiones estratégicas para adquirir un título de nobleza que confirmase su estatus. ${ }^{22}$

Es innecesario insistir en que la renta feudal constituye la base de la formación patrimonial en la Baja Edad Media. La elite financiera y mercantil zaragozana se dedicó a formas privilegiadas de circulación y acumulación de riqueza como el arrendamiento de grandes impuestos o rentas, y la compra de señoríos, dado que la rentabilidad del dinero se encontraba en la banca de depósito, pero ésta no era capaz todavía a finales de la Edad Media de absorber toda la demanda. Los arrendamientos de derechos señoriales e impuestos ocuparon una parte muy importante (tanto por su volumen como por su extensión 
geográfica) de las actividades de sus miembros. ${ }^{23}$ Desde el nivel más local hasta la hacienda regia, pasando por arcedianatos y Comunidades de aldeas, todos ellos intentaban apuntalar sus cuentas con el arriendo de sus fuentes de ingresos ordinarias y extraordinarias, cuya percepción se entregó a grandes mercaderes. El análisis de estas actividades ha visibilizado una especialización de las personas dedicadas la práctica mercantil en Aragón y una tendencia en el interés de las grandes empresas por determinadas rentas. Así, Donsancho, Coscó y Casaldáguila estuvieron inmersos en negocios financieros creados y protegidos por el Estado (generalidades, fogaje, quema), pero no actuaron a nivel local (sisas, bienes de propios, etc.).

Las fortunas amasadas en la inversión en proyectos de riesgo (comercio, finanzas) buscaban rentabilizar el capital que se apartaba para otros cometidos y encontraron la estabilidad y el prestigio en la adquisición de bienes raíces. Es más, el recurso al sistema de crédito a largo plazo como estrategia de promoción social resultaría un rasgo definitorio. La necesidad de liquidez de las instituciones y particulares aragoneses convirtió el negocio eventual del préstamo en una inversión duradera para la elite de negocios zaragozana de comienzos del siglo xv gracias a la consolidación del censal como fórmula de aplazamiento de la deuda (García Marsilla, 2002). Además de cubrir una necesidad de seguridad, la deuda consolidada permitió la rápida extensión geográfica y penetración local de las grandes fortunas mercantiles de la capital del reino. Fue la afirmación de su supremacía sobre otros poderes.

El análisis de los destinos nos permitió descartar la inversión en medios de producción (industrial o agraria) como objetivo prioritario del capital de la elite financiera y mercantil zaragozana. Es más, el inmobiliario no es para sus miembros un negocio en sí mismo (a pesar de los productos financieros desarrollados como un sistema hipotecario), pues el capital invertido y los ingresos derivados de las rentas sobre bienes inmuebles son una pequeña parte del patrimonio de la empresa familiar. Comprobamos la adquisición de inmuebles por parte de Donsancho, Coscó y Casaldáguila en una fase temprana de formación del patrimonio familiar y societario. Se organizaba su gestión para la percepción de rentas al mismo tiempo que se creaba un espacio para los negocios en torno a la vivienda familiar y la tienda. La concentración en un mismo barrio de la parentela, empleados, socios y dependientes, próximos entre sí,

23 En la vecina Castilla se observa una dinámica muy semejante a pesar de las diferencias institucionales y composición de sus elites: Collantes de Terán/Bonachía, 2010. 
afirmaba su presencia en la ciudad ${ }^{24} \mathrm{y}$, muy especialmente, facilitaba el acopio de parcelas de poder dentro de la circunscripción de la parroquia para acceder a los oficios municipales. En este sentido, no debemos dejar de lado la compra de señoríos, concebida como inversión económica, pero sobre todo como pieza fundamental en la promoción social de la elite de negocios aragonesa de comienzos del siglo xv, como demuestra que Beltrán de Coscó instituyera en sus últimas voluntades dos mayorazgos gracias a la compra de sendos señoríos en Aragón; una dinámica de adquisición que siguieron sus hijos y los de Ramón de Casaldáguila, que optaron, de hecho, por participar en la vida política aragonesa desde el estamento nobiliario.

La instalación definitiva en Zaragoza de estas empresas no supuso, como era previsible, la ruptura de lazos con sus comunidades de origen, tal y como hemos señalado a la hora de identificar a sus colaboradores. Así lo atestiguan los legados testamentarios hechos por Beltrán de Coscó a instituciones pías y caritativas, pero también a la restauración de la muralla de Tárrega. Es más, su familia se hizo cargo en la capital aragonesa de la educación de dos hijos de su hermano, capiscol en Tortosa, al igual que hizo Ramón de Casaldáguila con un hijo natural de Pere de Casaldáguila. Pero, al mismo tiempo, no descuidaron su inserción en la comunidad de acogida, sino que se involucraron en la vida diaria de la ciudad: ofrecían liquidez a las familias importantes y adelantaban dinero a las instituciones, alquilaban inmuebles a sus empleados y a la gente de su entorno, y dirimían diferencias mediante arbitrajes (generalmente en asuntos profesionales). La 'casa' fue la unidad básica de cohesión y depósito de capital simbólico de las tres grandes empresas zaragozanas. Este círculo próximo de relaciones personales y profesionales comprendía a empleados y sirvientes, una camarilla de escuderos y jóvenes dependientes que les acompañaban, e incluso a los notarios, que llegaron a denominar 'de casa'.

El uso intensivo de los vínculos de parentesco en su organización económica sirvió de aglutinante para conformar una fuerte interacción social basada en prácticas familiares (sucesorias, patrimoniales, matrimoniales y educativas) orientadas a la reproducción, transmisión y reagrupamiento del patrimonio. ${ }^{25}$ A este respecto, mientras los matrimonios de los empleados buscaban hacer fuertes los lazos que conectaban a los miembros de la empresa (Nicolau Cos-

24 Véase esta idea desarrollada en Guerreau-Jalabert, 1990.

25 Este comportamiento sigue los esquemas esenciales observados entre los mercaderes toscanos en Barcelona y los 'magnates' florentinos para asegurar un espacio que estaba discutido (por diferentes razones en cada caso): Soldani, 2004; Klapisch-Zuber, 2006. 
có, gestor de la tienda de Barcelona, casó con una hija de Domingo Sancho, socio de la compañía en la ciudad condal, y Juan de Mur acordó el matrimonio de María Heredia, sobrina suya, con Miguel Homedes, regente de su botiga), los enlaces de la segunda generación muestran otra estrategia, que rompía con la tendencia observada en los ciudadanos de Zaragoza de buscar afinidad profesional y perseguía, en su lugar, establecer relaciones sociales con familias que poseían un mayor capital simbólico o social. Angelina Sesvalls y Beltrán de Coscó casaron a sus hijas e hijos con Ramón de Mur, Baile General de Aragón, Juan de Moncayo, camarlengo del rey, Catalina Jiménez Cerdán, hija del Justicia de Aragón, María Enríquez de Lacarra, hija del mariscal de Navarra, y Violante Benedit, hija y hermana de mercaderes zaragozanos. En pocas palabras, las trayectorias analizadas son el resultado de una confluencia de educación, privilegio y matrimonio, ${ }^{26}$ y en la ejecución de estas estrategias para la promoción y reproducción social, las mujeres que integraban sus filas tuvieron un papel diferenciado de los hombres en muchos aspectos, pero igualmente imprescindible. Éstas pusieron en práctica cotidianamente unos conocimientos técnicos que compartían con sus parientes y subordinados, lo que las colocó en un lugar visible (De la Torre, 2014b). Los hijos varones que Eulalia de Voltres y Violante Satorre tuvieron con Ramón de Casaldáguila dividieron sus oportunidades de futuro entre Cataluña y Aragón. Mientras los mayores fueron orientados a la carrera militar, los menores lo hicieron al estudio del derecho canónico y a la carrera burocrática al servicio del tesorero del rey. Y aunque Bernat de Coscó, el menor de la familia, fue dirigido hacia la mercaduría por matrimonio y herencia, decidió armarse caballero e incluso protagonizar sonadas gestas cortesanas.

La reproducción social es, en definitiva, la perpetuación del dominio económico, pero la base social de la elite en la que se insertaban las tres grandes empresas que nos ocupan se encontraba en modelos culturales preexistentes compartidos con otros grupos de poder (Narbona, 2013), en los que la cultura caballeresca aportaba el papel simbólico en los procesos de dominación y las ideologías urbanas introducían en los argumentos de distinción el concepto de 'res publica' y de 'bonnum comune', aunque tenía como rasgo definitorio el protagonismo de las relaciones basadas en la confianza y en los lazos clientelares (inherentes al desarrollo de actividades económicas en las sociedades

26 Tres ejes sobre los que se construye el predominio social de la burguesía barcelonesa de comienzos del siglo xx: McDonogh, 1988. 
preindustriales), que se aseguraban al compartir espacios de sociabilidad. ${ }^{27} \mathrm{El}$ convento de San Francisco era sede de la cofradía de Santa Eulalia (de los mercaderes catalanes) y albergó los enterramientos de los integrantes de las grandes empresas analizadas y de su círculo social. Los frailes menores y Juan Donsancho acordaron en 1381 entregar una capilla al mercader para su familia frente a la puerta mayor de la iglesia, donde celebrarían sus aniversarios ante un altar erigido en honor de san Francisco. Por las mismas fechas, Miguel de Capiella encargaba un retablo al pintor Guillem de Leví y el costeado por Beltrán de Coscó sirvió en 1399 de modelo para otro retablo pintado por Juan de Leví. En la capilla de Santa María de los Ángeles, levantada a expensas de la cofradía de los catalanes, se enterró Arnalt de Araus. Ramón de Casaldáguila eligió el claustro como lugar de enterramiento, junto al cual quiso que descansaran sus restos Juan Ferriz, empleado del manresano y después de la compañía Torralba. Otro colaborador de esta última, el escudero Juan de Mur, que era originario de Tarazona, optó por una capilla dedicada a san Antonio de Padua, junto al ingreso del templo. Las grandes empresas trabajaron simultáneamente en integrarse en la comunidad local (sus miembros más destacados figuraban en primer lugar en las reuniones de sus respectivas parroquias, allí erigían una capilla familiar y donaban paños de oro) y en diferenciarse según unos derechos y privilegios propios, como la pertenencia a la cofradía de Santa María de Predicadores, conocida como 'de los mercaderes'.

No debe perderse de vista la importancia de espacios privilegiados de convivencia que facilitaban la proyección social, tales como las reuniones del concejo de la ciudad, de los brazos del reino en Cortes o las celebraciones de la monarquía. En la vida política, los varones de la elite de negocios destacaron por sus habilidades contables y de gestión, lo que derivó en el desempeño de los cargos públicos de mayor prestigio. ${ }^{28}$ Aunque queda pendiente esclarecer si éstos buscaban la intervención en la vida pública como muestra de su poder financiero y acceder así a la definitiva promoción social, o si bien planeaban la carrera política para estimular la promoción económica, ${ }^{29}$ la liberación de las obligaciones empresariales por delegación en socios y administradores permitió a Beltrán de Coscó y Ramón de Casaldáguila dedicarse en los últimos años de sus vidas a los asuntos políticos de la ciudad y el reino, de donde pudieron

27 No es necesario insistir en la especificidad de una cultura mercantil: Igual, 2009.

28 En Coulon, 2013, su autor mide la relación entre el comercio de largo recorrido y el gobierno de la ciudad de Barcelona al final de la Edad Media.

29 Véase un análisis de estas prácticas en la ciudad de Valencia en Furió, 1999. 
surgir los contactos que cristalizaron en sendas alianzas matrimoniales para su descendencia en ambos casos. De este modo, la dedicación a la vida políticoadministrativa encajaría dentro de una estrategia global: tras las fases de acumulación de capital económico, éste se transformaría en capital simbólico para instalarse definitivamente entre los grupos privilegiados de la sociedad de la Corona de Aragón.

\section{Aragón al filo de la Modernidad (conclusiones generales)}

Uno de los resultados de la investigación doctoral fue identificar como el perfil predominante entre la elite mercantil y financiera del reino de Aragón de comienzos del siglo xv al ciudadano de Zaragoza que se definía profesionalmente como mercader y la tienda como pieza fundamental de la estructura empresarial. En este sentido, la tesis intentó mostrar la variación en la naturaleza de los negocios de acuerdo a un escenario político, económico y social concreto, cuya secuencia entre 1380-1430 sería la siguiente: importación de tejidos desde el norte de Europa y exportación de paños catalanes y del sur de Francia a Castilla, suministro de materias primas para el sector manufacturero en la cuenca del Mediterráneo y a través del Canal de la Mancha, concentración del negocio en la corte real, y finalmente, financiación de las instituciones locales y regionales. La elección de la capital aragonesa como base de operaciones supuso una expansión del volumen de comercio y flujo de capital, junto a un incremento de los beneficios para los agentes económicos más dinámicos de la ciudad. Al fijar nuestra atención en la empresa como la base de la organización social, económica y política de su elite financiera y mercantil a comienzos del siglo XV verificamos la adaptación de las estructuras familiares y corporativas hacia la acumulación de capital y la reproducción social. Sus miembros encontraron acomodo en la política regional y en la administración real haciéndose un hueco entre unos grupos de poder que se vieron forzados a redefinirse y reconocer a este poder emergente..$^{30}$

Para finalizar, merece la pena detenerse en una serie de cuestiones clave que subyacen a lo largo de toda la tesis doctoral. La primera de ellas es el papel dominante de un limitado número de empresas que controlaban la economía del reino desde Zaragoza y que constituyen sólo una parte exitosa de un amplio

30 Sobre la nueva visión de la labor de los mercaderes, véanse los volúmenes colectivos Franceschi/ Goldthwaite/Mueller, 2007; Zorzi/Gamberini/Genet, 2011; Tanzini/Tognetti, 2012. 
abanico de operadores catalanes que actuaban en Aragón. El escenario local había cambiado claramente en la segunda mitad del siglo XIV, acompañado de un flujo de capital (también humano) que alcanzó el reino y que hizo posible que se estableciesen las condiciones idóneas para la creación de una activa elite de negocios en su capital. Se trata de una generación que converge en 1400, comenzando por Donsancho y Coscó, y continuada por Casaldáguila tras el Compromiso de Caspe. La cristalización de este grupo privilegiado integrado por unos cuarenta individuos no se explica por una ausencia de competencia; al contrario, se vio favorecida por una inteligente alineación con los intereses de la región.

El segundo aspecto a tener en cuenta es su especialización: mientras Donsancho se centraba en la financiación directa de la monarquía, Coscó operaba en el aspecto comercial del negocio y Casaldáguila se volcó en el crédito a las instituciones aragonesas. Por último, destaca la continuidad de las actividades. Esto es particularmente evidente en las conexiones entre Casaldáguila y la compañía Torralba. Juan de Mur tomó el relevo del manresano como arrendador de las generalidades y tesorero del General de Aragón, mientras Juan Fexas se dedicó al comercio a gran escala por la ruta del Ebro. Un fenómeno de reemplazo generacional sin traumas que permitió que la empresa de Donsancho desapareciera por la falta de apoyos y la extinción biológica, que los miembros de la familia Coscó no abandonaran los negocios, a pesar de centrarse en la gestión de sus señoríos, y que los Casaldáguila capitalizaran la riqueza, títulos nobiliarios y contactos acumulados para asentarse entre las clases privilegiadas en Cataluña y Aragón.

Por último, entre las contribuciones que pueden extraerse de esta tesis destaca la caracterización económica de Zaragoza en la Edad Media. ${ }^{31}$ La participación de su elite de negocios en todos los niveles del crédito y el recurso a todas las fórmulas a su alcance nos lleva a plantearnos la omnipresencia del crédito en la vida económica de la ciudad hacia $1400,{ }^{32}$ una de las innovaciones técnicas que permitieron el establecimiento de estas empresas a través de complejas redes mercantiles, que tuvieron su impacto en los sistemas productivos y comerciales, dada su importancia social y política (Sesma/Laliena, 2009).

En definitiva, el dominio de este reducido grupo de profesionales de los negocios es un tema con una elevada capacidad explicativa para comprender

31 Un estado de la cuestión en Barraqué, 1999.

32 Más allá incluso de lo planteado en Lara, 1983. 
nuestro presente, pues, como definían Karl Marx y Friedrich Engels en La ideología alemana: «las ideas de la clase dominante son las ideas dominantes en cada época; o, dicho en otros términos, la clase que ejerce el poder material dominante en la sociedad es, al mismo tiempo, su poder espiritual dominante». ${ }^{33}$ Y, dados los nuevos interrogantes que han ido surgiendo durante la realización de la tesis doctoral, este capítulo está todavía abierto.

\section{Referencias bibliográficas}

ABULAFIA, D. (2005), «Mercati e mercanti nella Corona d'Aragona: il ruolo degli imprenditori stranieri», en Rafael Narbona (coord.), La Mediterrània de la Corona d'Aragó: segles XIII-XVI, Valencia, Universitat de València, 797-820.

ÁLVAREZ-NOGAL, C., y PRADOS DE LA ESCOSURA, L. (2013), «The Rise and Fall of Spain, 1270-1850», Economic History Review 66, 1, 1-37.

AURELL CARDONA, J. (1996), Els mercaders catalans al Quatre-cents: mutació de valors i procés d'aristocratització a Barcelona (1370-1470), Lérida, Pagès.

BARRAQUÉ, J-P. (1999), Saragosse à la fin du Moyen Age: une ville sous influence, París, L'Harmattan.

BAVEL, B. J. P. van, y SCHOFIELD, P. R. (2008), The development of leasehold in north-western Europe, c. 1200 - 1600, Turnhout, Brepols.

BLASCO MARTÍNEZ, A. (2009), «Alazar Golluf, regente de la tesorería de la reina de Aragón, y su entorno familiar (siglos XIII-XV)», en F. Sabaté y C. Denjean (eds.), Cristianos y judíos en contacto en la Edad Media: polémica, conversión, dinero y convivencia, Lérida, Milenio, 481-580.

BLOCKMANS, W. (1996), «La manipulation du consensus. Systèmes de pouvoir a la fin du Moyen Âge», en S. Gensini (coord.), Principi e città alla fine del Medioevo, Ospedaletto, Pacini-Comune di San Miniato, 433-447.

BRITNELL, R. H. (2001), «Local trade, remote trade: Institutions, information and market integration, 1050-1330», en S. Cavaciocchi (ed.), Fiere e mercati nella integrazione delle economie europee. Secc. XIII-XVIII, Florencia, Le Monier, 185203.

BUYLAERT, F. (2015), «Lordship, Urbanization and Social Change in Late Medieval Flanders», Past and Present, 227, 31-75.

CARRÈRE, C. (1977-1978), Barcelone: 1380-1462. Un centre economic en epoca de crisi, Barcelona, Curial.

CASADO ALONSO, H. (2015), «Circuitos comerciales y flujos financieros en Castilla a fines de la Edad Media e inicios de la Modernidad», Estados y mercados fi-

33 Marx/Engels, 2014 (sin paginación). 
nancieros en el Occidente cristiano (siglos XIII-XVI), Pamplona, Gobierno de Navarra, 273-308.

CASADO ALONSO, H., y ROBLEDO HERNÁNDEZ, R., eds. (2002), Fortuna y Negocios: Formación y Gestión de los Grandes Patrimonios (siglos XVI-XX), Valladolid, Secretariado de Publicaciones de la Universidad de Valladolid.

COLLANTES DE TERÁN SÁNCHEZ, A., y BONACHÍA HERNANDO, J. A., coords. (2010), Fuentes para el estudio del negocio fiscal y financiero en los reinos hispánicos (siglos XIV-XVI), Madrid, Instituto de Estudios Fiscales.

CONDE DELGADO DE MOLINA, R. (1988), «Las actividades y operaciones de la banca barcelonesa trecentista de Pere Descaus y Andreu d'Olivella», Revista española de financiación y contabilidad, 55, 115-182.

COULON, D. (2004), Barcelone et le grand commerce d'Orient au Moyen Âge: un siècle de relations avec l'Égypte et la Syrie-Palestine (ca. 1330-ca. 1430), Madrid, Casa de Velázquez Barcelona, Institut Europeu de la Mediterrània.

COULON, D. (2013), «Ruling Class and Long-Distance Trade in Barcelona at the End of the Middle Ages», en M. Asenjo (coord.), Urban elites and aristocratic behaviour in the Spanish Kingdoms at the End of the Middle Ages, Turnhout, Brepols, 133-142.

COULON, D., coord. (2010), Réseaux marchands et réseaux de commerce: concepts récents, réalités historiques du Moyen Âge au XIX ${ }^{e}$ siècle, Estrasburgo, Presses Universitaires de Strasbourg.

CRUSELLES GÓMEZ, E. (2001), Los mercaderes de Valencia en la Edad Media, Lérida, Milenio.

DIAGO HERNANDO, M. (2013), «La irrupción de los mercaderes catalanes en el interior de la península Ibérica durante el siglo XIV. El ejemplo de los vecinos de Puigcerdà», en J. Mutgé, R. Salicrú y C. Vela (coords.), La Corona catalanoaragonesa, l'Islam i el món mediterrani, 211-220.

DIJKMAN, J. (2011), Shaping Medieval Markets: The Organisation of Commodity Markets in Holland, c. 1200-c. 1450, Leiden, Brill.

DUMOLYN, J. (2013), «Later Medieval and Early Modern elites: social categories and social dynamics» en M. Asenjo (coord.), Urban elites and aristocratic behaviour, 3-18.

EPSTEIN, S. R. (2009), Libertad y crecimiento. El desarrollo de los estados y de los mercados en Europa, 1300-1750, Valencia, Universitat de València.

EIXIMENIS, F. (1980), Regiment de la cosa pública, Barcelona, Editorial Barcino (ed. facsímil 1927).

FALCÓN PÉREZ, M. ${ }^{a}$ I. (2010), Ordinaciones reales otorgadas a la ciudad de Zaragoza en el siglo XV: de Fernando I a Fernando II, Zaragoza, Institución Fernando el Católico.

FALCÓN PÉREZ, M. a I. (2011) Alteraciones en Zaragoza en los años que precedieron al Compromiso de Caspe, Zaragoza, Institución Fernando el Católico. 
Hacer fortuna en la expansión mercantil bajomedieval. Tres grandes empresas de negocios...

FANFANI, T., ed. (2003), Alle origini della banca. Mercanti-banchieri e sviluppo economico, Roma, Bancaria Editrice.

FRANCESCHI, F., GOLDTHWAITE, R. A., y MUELLER, R. C., coords. (2007), Il Rinascimento italiano e l'Europa, IV. Commercio e cultura mercantile, TrevisoCostabissara, Fondazione Cassamarca.

FURIÓ DIEGO, A. (1999), «Deuda pública e intereses privados. Finanzas y fiscalidad municipales en la Corona de Aragón», Edad Media. Revista de historia, 2, 35-80.

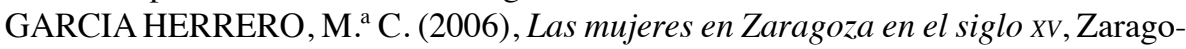
za, Prensas Universitarias de Zaragoza ( $1^{\mathrm{a}}$ ed. 1990).

GARCÍA MARSILLA, J. V. (2002), Vivir a crédito en la Valencia medieval: de los orígenes del sistema censal al endeudamiento del municipio, Valencia, Universitat de València.

GELDERBLOM, O. (2013), Cities of commerce: the institutional foundations of international trade in the Low Countries, 1250-1650, Princeton, Princeton University Press.

GOLDTHWAITE, R. A. (1968), Private wealth in Renaissance Florence: a study of four families, Princeton, Princeton University Press.

GREIF, A. (2006), Institutions and the path to the modern economy: lessons from medieval trade, Cambridge, Cambridge University Press.

GUARDUCCI, A., coord. (1990), Gerarchie economiche e gerarchie sociali: secoli XI I-XVIII, Florencia, Le Monier.

GUERREAU-JALABERT, A. (1990), «El sistema de parentesco medieval: sus formas (real/espiritual) y su dependencia con respecto a la organización del espacio», en R. Pastor de Togneri (coord.), Relaciones de poder, de producción y de parentesco en la Edad Media y Moderna: aproximación a su estudio, Madrid, CSIC, 85-105.

GUIRAL-HADZIIOSSIF, J. (1989), Valencia: puerto mediterráneo en el siglo XV (1410-1525), Valencia, Alfons el Magnànim, Institució Valenciana d'Estudis i Investigació.

HUNT, E. S., y MURRAY, J.M. (1999), A history of business in medieval Europe, 1200-1550, Cambridge, Cambridge University Press.

IGUAL LUIS, D. (1998), Valencia e Italia en el siglo XV. Rutas, mercados y hombres de negocios en el espacio económico del Mediterráneo occidental, Castellón, Bancaixa.

IGUAL LUIS, D. (2009) «Una aproximación a la cultura mercantil en los reinos hispánicos de la Baja Edad Media», en P. Boucheron y F. Ruiz, Modelos culturales y normas sociales al final de la Edad Media: Estado, Iglesia y sociedad, Cuenca, Universidad de Castilla-La Mancha, 273-308.

IGUAL LUIS, D. (2013) «Social Rise of the Mercantile Elite in Cities of the Medieval Kingdom of Valencia», en M. Asenjo (coord.), Urban elites and aristocratic behaviour, 161-170. 
IGUAL LUIS, D. (2014), «La circulación de capitales. El mundo financiero europeo en la Baja Edad Media» en F. Sabaté Curull y M. Pedrol (eds.), El mercat: un món de contactes $i$ intercanvis, Lérida, Pagès,.

IRANZO MUÑ̃́O, M. ${ }^{\mathrm{a}}$ T. (2005), Elites políticas y gobierno urbano en Huesca en la Edad Media, Huesca, Ayuntamiento de Huesca.

KLAPISCH-ZUBER, C. (2006), Retour à la cité. Les magnats de Florence, 13401440, París, École des hautes études en sciences sociales.

KOWALESKI, M. (1995), Local Markets and Regional Trade in Medieval Exeter, Cambridge, Cambridge University Press.

LAFUENTE GÓMEZ, M. (2015), «José Ángel Sesma Muñoz. Trayectoria académica e itinerarios historiográficos», Aragón en la Edad Media, 26, 29-71.

LAFUENTE GÓMEZ, M. (2016), «Anhelos de transparencia. Inspección y reforma de la gestión municipal en Zaragoza a finales del siglo XIV (1391-1400)» en C. Laliena y M. Lafuente (coords.), Consumo, comercio y transformaciones culturales en la Baja Edad Media: Aragón, siglos XIV-XV, Zaragoza, Grupo CEMA-Prensas Universitarias de Zaragoza, 147-183.

LALIENA CORBERA, C. (2010), «Las transformaciones de las elites políticas de las ciudades mediterráneas hacia 1300. Cambios internos y movilidad social» en S. Carocci (ed.), La mobilità sociale nel medioevo, Roma, École Française de Rome, 147-185.

LALIENA CORBERA, C. (2012), «Transformación social y revolución comercial en Aragón: treinta años de investigación», en C. LALIENA y M. LAFUENTE (coords.), Una economía integrada. Comercio, instituciones y mercados en Aragón (1300-1500), Zaragoza, Grupo CEMA-Universidad de Zaragoza, 13-68.

LALIENA, C., y LAFUENTE, M., coords. (2012), Una economía integrada. Comercio, instituciones y mercados en Aragón (1300-1500), Zaragoza, Grupo CEMAUniversidad de Zaragoza.

LARA IZQUIERDO, P. (1983), «Fórmulas crediticias medievales en Aragón. Zaragoza, centro de orientación crediticia (1457-1486) », Revista de Historia Jerónimo Zurita, 45-46, 7-90.

LOZANO GRACIA, S. (2008), Las elites en la ciudad de Zaragoza a mediados del siglo XV. La aplicación del método prosopográfico en el estudio de la sociedad, Zaragoza, [Tesis Doctoral inédita, disponible en https://zaguan.unizar.es/re$\operatorname{cord} / 7400]$.

MCDONOGH, G. W. (1988), Las buenas familias de Barcelona: historia social de poder en la era industrial, Barcelona, Omega.

MADDALENA, A. di (1990), «La ricchezza come nobiltà, la nobiltà come potere (secoli XV-XVIII): nodi storici e storiografici (dal 'mito della borghesia' al 'mito dell'aristocrazia')», en A. Guarducci (coord.), Gerarchie economiche e gerarchie sociali secoli XII-XVIII, Florencia, Le Monnier, 325-358. 
Hacer fortuna en la expansión mercantil bajomedieval. Tres grandes empresas de negocios...

MAINÉ BURGUETE, E. (2006), Ciudadanos honrados de Zaragoza. La oligarquía zaragozana en la Baja Edad Media (1370-1410), Zaragoza, Grupo CEMA-Universidad de Zaragoza.

MARSHALL, R. K. (1999), The local merchants of Prato. Small Entrepreneurs in the late medieval economy, Baltimore, The Johns Hopkins Universtity Press.

MARX, K., y ENGELS, F. (2014), La ideología alemana. Traducción de Wenceslao Roces, Madrid, Ediciones Akal, [e-libro].

MOKYR, J. (2008), Los dones de Atenea. Los orígenes históricos de la economía del conocimiento, Madrid, Marcial Pons Historia.

MURRAY, J. M. (2005), Bruges, cradle of capitalism, 1280-1390, Cambridge, Cambridge University Press.

NARBONA VIZCAÍNO, R. (2013), «Cultura política y comunidad urbana: Valencia, siglos XIV-XV», Edad Media: revista de historia, 14, 171-211.

NAVARRO ESPINACH, G. (2014), «Estudios recientes y proyectos actuales sobre los mercados medievales en Aragón y Valencia en pos de una historia comparada», en F. Sabaté (ed.), El mercat. Un món de contactes i intercanvis, Lérida, Pagès, 157-166.

NIGRO, G., coord. (2010), Francesco di Marco Datini: l'uomo, il mercante, Florencia, Fondazione Istituto internazionale di storia economica F. Datini-Firenze University Press.

OGILVIE, S. (2011), Insitutions and European Trade: Merchant Guilds, 1000-1800, Cambridge, Cambridge University Press.

ORLANDI, A. (2014), «Networks and Commercial Penetration Models in the Late Medieval Mediterranean: Revisiting the Datini», en A. Caracausi y C. Jeggle (coords.), Commercial networks and European cities 1400-1800, Londres, Brookfield, Vt. Pickering \& Chatto, 81-106.

ORTÍ GOST, P. (1998), El Patrimoni reial a la ciutat de Barcelona: segles XIII $i$ XIV, Barcelona.

PRIOTTI, J-P. (2002), «Uso material e inmaterial del dinero: un análisis social para el estudio de los patrimonios mercantiles, siglo XVI-XVII», en R. Robledo e H. Casado (coords.), Fortuna y negocios: formación y gestión de los grandes patrimonios (siglos XVI-XX), Valladolid, Universidad de Valladolid, 45-72.

REYERSON, K. L. (1985), Business, banking and finance in medieval Montpellier, Toronto, Pontifical Institute of Mediaeval Studies.

RIU, M. (1990), «La banca i la societat a la Corona, a finals de l'Etat Mitjana i començaments de la Moderna», Acta historica et archaeologica mediaevalia, 11/12, 187-224.

SABATÉ, F. (2008), «Oligarchies and social fractures in the cities of Late Medieval Catalonia», en M. Asenjo (ed.), Oligarchy and patronage in Spanish late medieval urban society, Turnhout, Brepols, 1-28. 
SÁNCHEZ MARTÍNEZ, M. (2006), «El mundo del crédito en la Corona de Aragón», en A. Pérez y G. Cruz (coords.), Hijos de Mercurio: banqueros, prestamistas, usureros y transacciones comerciales en el mundo mediterráneo, Madrid, Ediciones Clásicas Málaga, 343-374.

SCHOFIELD, P. R., y MATHEW, N. J. (2002), Credit and debtin Medieval England, c. 1180-c. 1350, Oxford, Oxford Books.

SESMA MUÑOZ (1991), J. Á., «Los Santángel de Barbastro: estructura económica y familiar», Aragón en la Edad Media, 9, 121-136.

SESMA MUÑOZ, J. Á., coord. (2010), La Corona de Aragón en el centro de su historia: aspectos económicos y sociales, Zaragoza, Grupo CEMA-Universidad de Zaragoza.

SESMA MUÑOZ, J. Á.(2013a), Revolución comercial y cambio social. Aragón y el mundo mediterráneo (siglos XIV-XV). Estudios reunidos por J. Á. García de Cortázar y Carlos Laliena, Zaragoza, Grupo CEMA-Universidad de Zaragoza.

SESMA MUÑOZ, J. Á.(2013b), «Las generalidades del Reino de Aragón. Su organización a mediados del siglo XV», Revolución comercial y cambio social, 95-158.

SESMA MUÑOZ, J. Á., y LALIENA CORBERA, C., coords. (2004), La población de Aragón en la Edad Media (siglos XIII-XV): estudios de demografía histórica, Zaragoza, Grupo CEMA-Universidad de Zaragoza.

SESMA MUÑOZ, J. Á., y LALIENA CORBERA, C. (2009) Crecimiento económico y formación de los mercados en Aragón en la Edad Media (1200-1350), Zaragoza, Grupo CEMA-Universidad de Zaragoza.

SOLDANI, M. E. (2004), «Alleanze matrimoniali e strategie patrimoniali nella Barcellona del XV secolo: i mercanti toscani fra integrazione e consolidamento della richezza», Archivio storico italiano, 162/4, 667-698.

SOLDANI, M. E. (2010) Uomini d'affari e mercanti toscani nella Barcellona del Quattrocento, Barcelona, CSIC.

STABEL, P. (1997), Dwarfs among giants. The Flemish urban network in the late Middle Ages, Lovaina/Apeldoorn, Garant.

TANZINI, L., y TOGNETTI, S., coords. (2012), Mercatura è arte: uomini d'affari toscani in Europa e nel Mediterraneo tardomedievale, Roma.

TANZINI, L., y TOGNETTI, S. (2014), Il governo dell'economia. Italia e Penisola Iberica nel basso Medioevo, Roma.

TORRE GONZALO, S. de la (2012a), «Elites mercantiles y financieras de Zaragoza en el primer tercio del siglo XV (1380-1430)», en Carlos Laliena Corbera y Mario Lafuente Gómez (coords.), Una economía integrada. Comercio, instituciones y mercados en Aragón (1300-1500), Zaragoza, 409-434.

TORRE GONZALO, S. de la (2012b), «Por hacer paz y justicia: la traición como arma política durante el Interregno en el reino de Aragón (1410-1412)»,e-Spania.Revue interdisciplinaire d'études hispaniques médiévales et modernes, [en línea], 14. 
Hacer fortuna en la expansión mercantil bajomedieval. Tres grandes empresas de negocios...

TORRE GONZALO, S. de la (2013a), «Mercaderes y políticos: Ramón de Casaldáguila, ciudadano de Zaragoza, y el Compromiso de Caspe», El Compromiso de Caspe (1412), cambios dinásticos y Constitucionalismo en la Corona de Aragón: Actas del XIX Congreso de Historia de la Corona de Aragón, Zaragoza, 863-871.

TORRE GONZALO, S. de la (2013b), «Fronteras en guerra: la defensa del reino de Aragón ante la invasión de los condes de Foix en 1396», Les frontières pyrrénéenees au Moyen Âge (VIe-XVe s.). Nouvelles thèses, nouveaux débats, Universidad Toulouse-Le-Mirail, FRAMESPA [en prensa].

TORRE GONZALO, S. de la (2014a), «La cultura escrita de la elite de negocios de Zaragoza y la economía del conocimiento hacia 1400», en J. Ángel Sesma Muñoz y Carlos Laliena Corbera (coords.), De la escritura a la historia (Aragón, siglos XIII-XV). Estudios dedicados a la profesora Cristina Monterde Albiac, Zaragoza, 125-146.

TORRE GONZALO, S. de la (2014b), «Mujeres de la elite mercantil de Zaragoza alrededor de 1400», en M. ${ }^{a}$ C. García Herrero y C. Pérez Galán (coords.), Mujeres de la Edad Media: Actividades políticas, socioeconómicas y culturales, Institución Fernando el Católico, Zaragoza, 199-216.

TREPPO, M. del, coord. (1994), Sistema di rapporti ed élites economiche in Europa (secoli XII-XVII), Nápoles.

VILLANUEVA MORTE, C., y LAFUENTE GÓMEZ, M., coords. (2015), Documentos del concejo de Zaragoza. Edición crítica de los fondos del Archivo Municipal. I: 1285-1348, Departamento de Historia Medieval, Universidad de Zaragoza, Zaragoza.

ZANDEN, J. L. van (2001), «A third road to Capitalism? Proto-industrialisation and the moderate nature of the Late Medieval crisis in Flanders and Holland, 13501550», en P. C. M. Hoppenbrouwers y J. L. van Zanden (eds.), Peasants into farmers? The transformation of rural economy and society in the Low Countries in $t$ he light of the Brenner debate, Turnhout, 85-101.

ZORZI, A., GENET, J-P, y GAMBERINI, A. (2011), The languages of political society: Western Europe, 14th-17th centuries, Roma.

ZUIJDERDUIJN, C. J. (2009), Medieval capital markets. Markets for renten, state formation and private investment in Holland (1300-1550), Leiden. 